\title{
Pengaruh Berat Badan Lahir Rendah dengan Kejadian Stunting pada Anak Usia 12-23 Bulan di Wilayah Kerja Puskesmas Lubuk Buaya Padang Tahun 2019
}

\author{
Linda Wati ${ }^{1}$, Monarisa ${ }^{2}$, Meta Rikandi ${ }^{3}$ \\ 1,2STIKes Alifah Padang \\ ${ }^{3}$ Akper Aisyiyah Padang

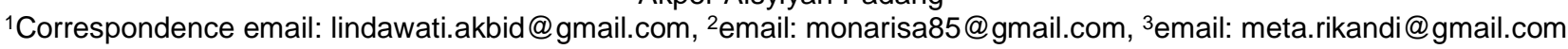

\begin{abstract}
Abstrak. Kejadian stunting (pendek) merupakan masalah gizi umum yang dihadapi di Indonesia. Prevalensi stunting berdasarkan data rikesdas pada tahun 2013 secara nasional tercatat sebanyak 37,2\% dari seluruh balita, sedangkan di Sumbar tercatat 39,2\% dari seluruh balita. Pada tahun 2018 angka stunting nasional tercatat 30,8\% dari seluruh balita dan angka Sumbar tercatat 30,0\% dari seluruh balita. Penelitian ini bertujuan untuk mengetahui pengaruh berat badan lahir rendah dengan kejadian stunting pada anak usia 12-23 bulan di Wilayah Kerja Puskesmas Lubuk Buaya Padang Tahun 2019. sampel dalam penelitian ini berjumlah 294 orang balita baik dengan stunting maupun tidak stunting. Analisis data yang digunakan yaitu univariat dan bivariat, dan multivariat. Hasil penelitian didapatkan tidak terdapat hubungan yang bermakna antara berat badan dengan kejadian stunting, terdapat hubungan yang bermakna antara riwayat infeksi dengan kejadian stunting, tidak terdapat hubungan yang bermakna antara pemberian ASI dengan kejadian stunting, terdapat hubungan yang bermakna antara pola asuh dengan kejadian stunting, faktor yang paling mempengaruhi kejadian stunting pada anak balita di Wilayah Kerja Puskesmas Lubuk Buaya Padang Tahun 2019 adalah pola asuh dengan nilai $p$ value $=0,002$. Pentingnya untuk pihak Puskesmas Lubuk Buaya Padang edukasi yang diberikan juga tidak hanya berfokus kepada sasaran saja, melainkan juga diberikan kepada keluarga terutama tentang pada ibu dengan anak balita.
\end{abstract}

Kata Kunci: BBLR; Kejadian Stunting

Abstract. Stunting (short) is a common nutritional problem faced in Indonesia. The stunting prevalence based on the National Health Survey in 2013 was recorded at 37.2\% of all children under five, while in West Sumatra it was recorded at $39.2 \%$ of all children under five. In 2018 the national stunting rate was recorded at 30.8\% of all toddlers and West Sumatra's figure was 30.0\% of all toddlers. This study aims to determine the effect of low birth weight with the incidence of stunting in children aged 12-23 months in the Work Area of Lubuk Buaya Public Health Center in Padang in 2019. The sample in this study amounted to 294 toddlers both with stunting and not stunting. Analysis of the data used is univariate and bivariate, and multivariate. The results showed there was no significant relationship between body weight with the incidence of stunting, there was a significant relationship between the history of infection with the incidence of stunting, there was no significant relationship between breastfeeding and the incidence of stunting, there was no significant relationship between parenting with the incidence of stunting, the most influencing factor for the incidence of stunting in children under five in the Work Area of the Lubuk Buaya Public Health Center in 2019 was parenting with a $p$ value $=0.002$. The importance of the Lubuk Buaya Public Health Center in Padang is not only focused on the target, but also on families, especially about mothers and children under five.

Keyword: low birth weigh; stunting

\section{PENDAHULUAN}

Masalah kekurangan gizi yang mendapat banyak perhatian akhir-akhir ini adalah masalah kurang gizi kronis yaitu dalam bentuk anak pendek atau stunting. Stunting merupakan salah satu menifestasi utama dari malnutrisi. Stunting adalah hasil sebuah proses patologis yang berhubungan dengan kegagalan untuk mencapai pertumbuhan linier potensial atau gagal mencapai tinggi badan relatif terhadap umur (WHO dalam Gibson, 2005). Anak dikatakan stunting jika memiliki panjang/tinggi badan menurut umur dibawah -2 standar deviasi median standar pertumbuhan anak (WHO, 2005).

Menurut Riset Dasar Kesehatan (Riskesdas) secara nasional di Indonesia dari tahun 2007 hingga 2013 menunjukkan angka stunting meningkat dari 36,8\% menjadi $37,2 \%$ yang berarti pertumbuhan tidak maksimal dialami oleh sekita 8 jta anak atau satu dari tiga anak Indonesia sehingga Indonesia masuk dalam peringkat kelima negara berkembang dunia yang memiliki prevalensi balita stunting terbanyak (UNICEF, 2009).
Berdasarkan data Dinas Kesehatan Sumatera Barat tahun 2015, prevalensi stunting di Kota Padang tahun 2015 sebesar 15\%. Prevalensi tertinggi berada di Kabupaten Solok dan prevalensi terendah berada di Kota Solok sedangkan Kota Padang berada pada urutan ke-13 dari 19 Kabupaten/Kota di Sumatera Barat. Stunting dianggap sebagai pengukuran yang tepat di situasi negara berkembang, dimana lingkungannya cenderung tidak kondusif untuk anak pada awal masa kehidupan untuk dapat tumbuh secara optimal (Vir et al., 2011) dan merupakan prediktor kurang gizi yang lebih baik daripada underweight (Black et al., 2008). Permasalahan gizi harus diperhatikan sejak masih dalam kandungan. Gizi ibu hamil menjadi faktor penting terhadap pertumbuhan dan perkembangan janin (Devi M. Analisis Faktor-Faktor yang Berpengaruh terhadap Status Gizi Balita di Pedesaan. Teknologi dan Kejuruan. 2010;33(2):183-192.)

Berdasarkan uraian diatas, penting dilakukan penelitian mengenai pengaruh berat badan lahir rendah dengan kejadian stunting pada anak usia 12-23 bulan di 
Wilayah Kerja Puskesmas Lubuk Buaya Padang Tahun 2019.

\section{METODE PENELITIAN}

Penelitian ini merupakan studi penelitian analitik dengan desain kasus kontrol (case control design) yaitu penelitian analitik yang menyangkut bagaimana faktor risiko dipelajari dengan menggunakan pendekatan retrospective. Sampel dalam penelitian ini adalah ibu dan anak umur 12-23 bulan di Wilayah Kerja Puskesmas Lubuk Buaya Padang dengan jumlah 294 orang.

\section{HASIL DAN PEMBAHASAN} Analisa Univariat

Tabel 1. Karakteristik Anak

\begin{tabular}{ccccc}
\hline Variabel & \multicolumn{2}{c}{ Kasus } & \multicolumn{2}{c}{ kontrol } \\
\hline Jenis kelamin & $\boldsymbol{f}$ & $\%$ & $\boldsymbol{f}$ & $\%$ \\
Laki-laki & 80 & 54 & 70 & 48 \\
Perempuan & 67 & 46 & 77 & 52 \\
Jumlah & $\mathbf{1 4 7}$ & $\mathbf{1 0 0}$ & $\mathbf{1 4 7}$ & $\mathbf{1 0 0}$ \\
& & & & \\
Berat badan lahir & & & & \\
BBLR & 8 & 5 & 3 & 2 \\
Normal & 139 & 95 & 144 & 98 \\
Jumlah & $\mathbf{1 4 7}$ & $\mathbf{1 0 0}$ & $\mathbf{1 4 7}$ & $\mathbf{1 0 0}$ \\
& & & & \\
Riwayat Penyakit & & & & \\
Infeksi & & & & \\
Ya & 146 & 99 & 14 & 10 \\
Tidak & 1 & 1 & 133 & 90 \\
Jumlah & $\mathbf{1 4 7}$ & $\mathbf{1 0 0}$ & $\mathbf{1 4 7}$ & $\mathbf{1 0 0}$
\end{tabular}

$\begin{array}{ccccc}\begin{array}{c}\text { Pemberian Asi } \\ \text { Ekslusif }\end{array} & & & & \\ \text { Ya } & 143 & 97 & 145 & 99 \\ \text { Tidak } & 4 & 3 & 2 & 1 \\ \text { Jumlah } & \mathbf{1 4 7} & \mathbf{1 0 0} & \mathbf{1 0 0} & \mathbf{1 0 0} \\ & & & & \\ \text { Pola Asuh } & & & & \\ \text { Baik } & 102 & 69 & 121 & 82 \\ \text { Kurang Baik } & 45 & 31 & 26 & 18 \\ \text { Jumlah } & \mathbf{1 4 7} & \mathbf{1 0 0} & \mathbf{1 4 7} & \mathbf{1 0 0}\end{array}$

Berdasarkan menunjukkan bahwa distribusi kasus stunting di Wilayah Kerja Puskesmas Lubuk Buaya Padang jenis kelamin lebih banyak pada kelompok kasus dengan jenis kelamin laki-laki 80 orang (54\%) dari kelompok kontrol 70 orang (48\%), Anak yang lahir dengan berat badan lahir rendah lebih banyak pada kelompok kasus sebanyak 8 orang $(5 \%)$ dari pada kelompok kontrol sebanyak 3 orang $(2 \%)$, Anak yang pernah mendapatkan riwayat penyakit infeksi lebih banyak pada kelompok kasus yaitu 146 orang (99\%) dari pada kelompok kontrol sebanyak 14 orang (10\%), Anak yang tidak mendapatkan ASI Ekslusif lebih banyak pada kelompok kasus 4 orang (3\%) dari pada kelompok kontrol 2 orang (1\%), Anak dengan pola asuh kurang baik lebih banyak pada kelompok kasus 45 orang (31\%) dari pada kelompok kontrol 26 orang (18\%) di Wilayah Kerja Puskesmas Lubuk Buaya Padang Tahun 2019.

\section{Analisa Bivariat \\ Hubungan Berat Badan Lahir Rendah dengan Kejadian Stunting}

Tabel 2. Hubungan Berat Badan Lahir Rendah dengan Kejadian Stunting

\begin{tabular}{|c|c|c|c|c|c|c|c|}
\hline \multirow{3}{*}{ Berat Badan } & \multicolumn{4}{|c|}{ Kejadian Stunting } & \multicolumn{2}{|c|}{ total } & \multirow[t]{3}{*}{ Nilai $p$} \\
\hline & \multicolumn{2}{|c|}{ Normal } & \multicolumn{2}{|c|}{ Stunting } & & & \\
\hline & $f$ & $\%$ & $f$ & $\%$ & $f$ & $\%$ & \\
\hline Normal & 144 & 49 & 139 & 47 & 283 & 96 & \\
\hline BBLR & 3 & 1 & 8 & 3 & 11 & 4 & 0,219 \\
\hline Total & 147 & 50 & 147 & 50 & 294 & 100 & \\
\hline
\end{tabular}

Berdasarkan tabel diatas dapat dilihat bahwa kejadian stunting lebih tinggi pada anak dengan BBLR 139 orang (47\%) dibandingkan anak dengan berat badan normal 8 orang $(3 \%)$. dari hasil uji statistik didapatkan $p$-value $0,219 \quad(<0,05)$ tidak terdapat hubungan yang bermakna antara berat badan dengan kejadian stunting pada anak di Wilayah Kerja Puskesmas Lubuk Buaya Padang Tahun 2019.

Hubungan Riwayat Infeksi dengan Kejadian Stunting

Tabel 3. Hubungan Riwayat Infeksi dengan Kejadian Stunting

\begin{tabular}{|c|c|c|c|c|c|c|c|}
\hline \multirow[t]{3}{*}{ Riwayat Infeksi } & \multicolumn{4}{|c|}{ Kejadian Stunting } & \multicolumn{2}{|c|}{ total } & \multirow[t]{3}{*}{ Nilai $p$} \\
\hline & \multicolumn{2}{|c|}{ Normal } & \multicolumn{2}{|c|}{ Stunting } & & & \\
\hline & $f$ & $\%$ & $f$ & $\%$ & $f$ & $\%$ & \\
\hline $\mathrm{Ya}$ & 133 & 48 & 146 & 52 & 279 & 100 & \\
\hline Tidak & 14 & 93 & 1 & 7 & 15 & 100 & 0,001 \\
\hline Total & 147 & 114 & 147 & 59 & 294 & 100 & \\
\hline
\end{tabular}

Berdasarkan tabel diatas dapat dilihat bahwa kejadian stunting lebih tinggi pada anak dengan riwayat infeksi 146 orang (52\%) dibandingkan anak dengan tidak ada riwayat infeksi 1 orang (7\%). dari hasil uji statistik didapatkan p-value $0,001 \quad(<0,05)$ terdapat hubungan yang bermakna antara riwayat infeksi dengan kejadian stunting pada anak di Wilayah Kerja Puskesmas Lubuk Buaya Padang Tahun 2019.

Hubungan Pemberian ASI dengan Kejadian Stunting 
Tabel 4. Hubungan Pemberian ASI dengan Kejadian Stunting

\begin{tabular}{|c|c|c|c|c|c|c|c|}
\hline \multirow{3}{*}{ Pemberian ASI } & \multicolumn{4}{|c|}{ Kejadian Stunting } & \multicolumn{2}{|c|}{ total } & \multirow[t]{3}{*}{ Nilai $p$} \\
\hline & \multicolumn{2}{|c|}{ Normal } & \multicolumn{2}{|c|}{ Stunting } & & & \\
\hline & $f$ & $\%$ & $f$ & $\%$ & $f$ & $\%$ & \\
\hline $\mathrm{Ya}$ & 145 & 50 & 143 & 50 & 288 & 100 & \\
\hline Tidak & 2 & 33 & 4 & 67 & 6 & 100 & 0,684 \\
\hline Total & 147 & 83 & 147 & 117 & 294 & 100 & \\
\hline
\end{tabular}

Berdasarkan tabel diatas dapat dilihat bahwa kejadian stunting lebih tinggi pada anak dengan pemberian ASI 145 orang (50\%) dibandingkan anak dengan tidak memberikan ASI 2 orang (33\%). dari hasil uji statistik didapatkan p-value $0,684(<0,05)$ tidak terdapat hubungan yang bermakna antara pemberian ASI dengan kejadian stunting pada anak di Wilayah Kerja Puskesmas Lubuk Buaya Padang Tahun 2019.

Hubungan Pola Asuh dengan Kejadian Stunting

Tabel 5. Hubungan Pola Asuh dengan Kejadian Stunting

\begin{tabular}{|c|c|c|c|c|c|c|c|}
\hline \multirow{3}{*}{ Pola Asuh } & \multicolumn{6}{|c|}{ Keiadian Stunting } & \multirow[t]{3}{*}{ Nilai $p$} \\
\hline & \multicolumn{2}{|c|}{ Normal } & \multicolumn{2}{|c|}{ Stunting } & \multicolumn{2}{|c|}{ total } & \\
\hline & $f$ & $\%$ & $f$ & $\%$ & $f$ & $\%$ & \\
\hline Baik & 121 & 54 & 102 & 46 & 223 & 100 & \\
\hline Kurang Baik & 26 & 37 & 45 & 63 & 71 & 100 & 0,014 \\
\hline Total & 147 & 91 & 147 & 109 & 294 & 100 & \\
\hline
\end{tabular}

Berdasarkan tabel diatas dapat dilihat bahwa kejadian stunting lebih tinggi pada anak dengan pola asuh baik (normal)121 orang (54\%) dibandingkan dengan pola asuh kurang baik 26 orang (37\%). dari hasil uji statistik didapatkan $p$-value $0,014(<0,05)$ terdapat hubungan yang bermakna antara pola asuh dengan kejadian stunting pada anak di Wilayah Kerja Puskesmas Lubuk Buaya Padang Tahun 2019.

\section{Analisa Multivariat}

Faktor Yang Paling Mempengaruhi Kejadian stunting

\begin{tabular}{cccccc}
\multicolumn{2}{c}{ Tabel 6 Faktor Yang Paling Mempengaruhi Kejadian stunting } \\
\hline & B & Sig. & Exp(B) & \multicolumn{2}{c}{ 95\%.C.I.For Exp (B) } \\
Lower & Upper \\
\hline Pola asuh & & & & 0,398 & 0,221 \\
Riwayat infeksi & $-0,921$ & 0,002 & 21,137 & 2,659 & 168.014 \\
constant & 3.051 & 0,004 & 0,107 & & \\
\hline
\end{tabular}

Berdasarkan tabel diatas didapatkan faktor yang paling mempengaruhi kejadian stunting pada anak balita di Wilayah Kerja Puskesmas Lubuk Buaya Padang Tahun 2019 adalah pola asuh dengan nilai $p$ value $=0,002$.

\section{Pembahasan \\ Karakteristik Anak}

Berdasarkan hasil penelitian menunjukkan bahwa distribusi kasus stunting di Wilayah Kerja Puskesmas Lubuk Buaya Padang jenis kelamin lebih banyak pada kelompok kasus dengan jenis kelamin laki-laki 80 orang (54\%) dari kelompok kontrol 70 orang (48\%), Anak yang lahir dengan berat badan lahir rendah lebih banyak pada kelompok kasus sebanyak 8 orang $(5 \%)$ dari pada kelompok kontrol sebanyak 3 orang (2\%), Anak yang pernah mendapatkan riwayat penyakit infeksi lebih banyak pada kelompok kasus yaitu 146 orang (99\%) dari pada kelompok kontrol sebanyak 14 orang (10\%), Anak yang tidak mendapatkan ASI Ekslusif lebih banyak pada kelompok kasus 4 orang (3\%) dari pada kelompok kasus 2 orang (1\%), Anak dengan pola asuh kurang baik lebih banyak pada kelompok kasus 45 orang (31\%) dari pada kelompok kontrol 26 orang (18\%) di Wilayah Kerja Puskesmas Lubuk Buaya Padang Tahun 2019.

Hasil penelitian ini sejalan dengan penelitian yang dilakukan oleh Anshori yang dilakukan di Kecamatan
Semarang Timur yang mendapatkan bahwa anak stunting banyak yang menderita infeksi.

\section{Hubungan Berat Badan Lahir Rendah dengan Kejadian Stunting}

Hasil penelitian didapatkan kejadian stunting lebih tinggi pada anak dengan BBLR 139 orang (47\%) dibandingkan anak dengan berat badan normal 8 orang (3\%). dari hasil uji statistik didapatkan p-value 0,219 $(<0,05)$ tidak terdapat hubungan yang bermakna antara berat badan dengan kejadian stunting pada anak di Wilayah Kerja Puskesmas Lubuk Buaya Padang Tahun 2019. hasil penelitian ini tidak sejalan dengan penelitian yang dilakukan Ristanti di wonosobo yang mendapatkan bahwa BBLR memiliki hubungan yang signifikan dengan kejadian stunting.

Berat badan lahir rendah adalah gambaran multimasalah kesehatan masyarakat yang mencakup ibu yang kekurangan gizi jangka panjang, kesehatan yang buruk, kerja keras dan perawatan kesehatan dan kehamilan yang buruk.

\section{Hubungan Riwayat Infeksi dengan Kejadian Stunting}

Hasil penelitian didapatkan kejadian stunting lebih tinggi pada anak dengan riwayat infeksi 146 orang (52\%) dibandingkan anak dengan tidak ada riwayat infeksi 1 orang (7\%). dari hasil uji statistik didapatkan $p$ value $0,001(<0,05)$ terdapat hubungan yang bermakna 
antara riwayat infeksi dengan kejadian stunting pada anak di Wilayah Kerja Puskesmas Lubuk Buaya Padang Tahun 2019.

Penelitian ini sejalan dengan penelitian dari Oktarina tahun 2012 yang mendapatkan bahwa penyakit infeksi memiliki hubungan yang signifikan terhadap kejadian stunting. Balita yang memiliki riwayat penyakit infeksi pada balita, maka akan lebih beresiko sebesar 4 kali daripada balita yang tidak memiliki riwayat penyakit infeksi penyakit. Infeksi adalah pertumbuhan organisme parasit didalam tubuh. Organisme parasit adalah salah satu yang hidup pada atau dalam organisme lain dan makanan yang menarik daripadanya.

\section{Hubungan Pemberian ASI dengan Kejadian Stunting}

Berdasarkan hasil penelitian didapatkan bahwa kejadian stunting lebih tinggi pada anak dengan pemberian ASI 145 orang (50\%) dibandingkan anak dengan tidak memberikan ASI 2 orang (33\%). dari hasil uji statistik didapatkan $p$-value $0,684 \quad(<0,05)$ tidak terdapat hubungan yang bermakna antara pemberian ASI dengan kejadian stunting pada anak di Wilayah Kerja Puskesmas Lubuk Buaya Padang Tahun 2019.

Hasil penelitian ini tidak sejalan dengan penelitian yang dilakukan oleh Hidayah tahun 2013 yang menemukan bahwa ada hubungan yang bermakna antara ASI Ekslusif dengan kejadian stunting pada anak balita. Akan tetapi, hasil penelitian ini sejalan dengan penelitian yang dilakukan oleh Anshori yang mendapatkan bahwa ASI Ekslusif bukan merupakan faktor resiko kejadian stunting pada anak balita.

\section{Hubungan Pola Asuh dengan Kejadian Stunting}

Berdasarkan hasil penelitian didapatkan bahwa kejadian stunting lebih tinggi pada anak dengan pola asuh baik (normal)121 orang (54\%) dibandingkan dengan pola asuh kurang baik 26 orang (37\%). dari hasil uji statistik didapatkan $p$-value $0,014(<0,05)$ terdapat hubungan yang bermakna antara pola asuh dengan kejadian stunting pada anak di Wilayah Kerja Puskesmas Lubuk Buaya Padang Tahun 2019.

Hasil penelitian ini sejalan dengan penelitian yang dilakukan oleh Yudianti (2016) terdapat hubungan pola asuh dengan kejadian stunting di Kabupaten Polewali Mandar. Banyak faktor yang mendukung terjadinya stunting pada anak. Kualitas asupan zat gizi serta paparan terhadap infeksi merupakan faktor utama penyebab gangguan pertumbuhan pada balita. Menyusui, memberi makanan yang sehat, memberi makanan yang bergizi dan mengontrol makanan yang dihabiskan dan meningkatkan status gizi anak (Sawadogo, et.al, 2015)

\section{Faktor yang Paling Mempengaruhi Kejadian stunting}

Berdasarkan hasil penelitian didapatkan faktor yang paling mempengaruhi kejadian stunting pada anak balita di Wilayah Kerja Puskesmas Lubuk Buaya Padang Tahun 2019 adalah pola asuh dengan nilai $p$ value $=0,002$. hasil penlitian yang dilakukan oleh Onetusfifsi (2015) didapatkan hasil penjaringan analisis multivariat dari variabel independen utama dan variabel kovariat menyatakan bahwa BBLR dan riwayat penyakit infeksi penyakit terdapat hubungan yang signifikan terhadap kejadian stunting pada anak usia 12-60 bulan.

\section{SIMPULAN}

1. Tidak terdapat hubungan yang bermakna antara Berat Badan dengan kejadian stunting ( $p$.value= $0,219)$ pada anak balita di Wilayah Kerja Puskesmas Lubuk Buaya Padang Tahun 2019.

2. Terdapat hubungan yang bermakna antara riwayat infeksi dengan kejadian stunting ( $p$.value $=0,01)$ pada anak balita di Wilayah Kerja Puskesmas Lubuk Buaya Padang Tahun 2019.

3. Tidak Terdapat hubungan yang bermakna antara pemberian ASI dengan kejadian stunting (p.value $=0,684$ ) pada anak balita di Wilayah Kerja Puskesmas Lubuk Buaya Padang Tahun 2019.

4. Terdapat hubungan yang bermakna antara pola asuh dengan kejadian stunting ( $p$.value $=0,014$ ) pada anak balita di Wilayah Kerja Puskesmas Lubuk Buaya Padang Tahun 2019.

5. Faktor yang paling mempengaruhi kejadian stunting pada anak balita di Wilayah Kerja Puskesmas Lubuk Buaya Padang Tahun 2019 adalah pola asuh dengan nilai $p$ value $=0,002$.

\section{DAFTAR PUSTAKA}

Arikunto, 2010. Prosedur Penelitian, Jakarta: PT. Rineka Cipta.

Balitbangkes. Riset Kesehatan Dasar. Jakarta: Kementerian Kesehatan RI; 2013.

DKK. Profil Kesehatan Kota Padang. Padang: Dinas Kesehatan Kota Padang; 2013.

DKK. Profil Kesehatan Kota Padang. Padang: Dinas Kesehatan Kota Padang; 2014

Elfindri. Child Malnutrition in Indonesia. Bulletin of Indonesia Economic Studies.1996;3:97-111.

Gibney MJ. Gizi Kesehatan Masyarakat. Jakarta: EGC; 2009.

Hidayah F. ASI Eksklusif sebagai Faktor Risiko Kejadian Stunting Pada Anak Usia 6-24 Bulan di Kota Yogyakarta. Yogyakarta: Universitas Gajah Mada; 2013.

Maryanto S, Anugrah RM. Hubungan antara penyakit tuberkulosis paru (Tb paru) dan BBLR dengan kejadian stunting pada siswa kelas 1 di SD negeri Sambek kecamatan Wonososbo. 2015

Oktarina Z. Hubungan Berat Lahir dan Faktor-Faktor Lainnya dengan Kejadian Stunting pada Balita Usia 24-59 Bulan di Provinsi Aceh, Sumatera Utara, Sumatera Selatan, dan Lampung pada Tahun 2010. Jakarta: Universitas Indonesia; 2012.

Proyek Kesehatan dan Gizi berbasis Masyarakat Untuk Mengurangi Stunting. In: Corporation MC, editor. Jakarta: MCA-Indonesia; 2014.

Rosha BC, Putri DSK, Putri IYS. Determinan Status Gizi Pendek Anak Balita dengan Riwayat Berat Badan Lahir Rendah di Indonesia (BBLR) dI INDONESIA (Analaisis Data Riskesdas 2007-2010). Jurnal Ekologi Kesehatan.2013;12:195-205

Rudert C. Malnutrition in Asia. Vientiane: UNICEF East Asia Pacific; 2014.

Stunting. The Indonesian Journal of Public Health. $2012 ; 8$. 
Sulastri D. Faktor Determinan Kejadian Stunting pada Anak Usia Sekolah di Kecamatan Lubuk Kilangan Kota Padang. Majalah Kedokteran Andalas. 2012;36.

UNICEF. Ringkasan Kajian Gizi. Jakarta: Pusat Promosi Kesehatan - Kementerian Kesehatan RI; 2012.

Welassih BD, Wirjatmadi RB. Beberapa Faktor yang Berhubungan dengan Status Gizi Balita

WHO. Child Growth Standar-malnutrition among children in poor area of china. Public Health Nutr.1991;12:8. 